\title{
Single port access for laparoscopic lateral segmentectomy
}

\author{
Yoshihiro Inoue, Mitsuhiro Asakuma, Fumitoshi Hirokawa, Michihiro Hayashi, Tetsunosuke Shimizu, \\ Kazuhisa Uchiyama \\ Department of General and Gastroenterological Surgery, Osaka Medical College Hospital, Osaka, Japan \\ Videosurgery Miniinv 2017; 12 (4): 357-365 \\ DOI: https://doi.org/10.5114/wiitm.2017.70260
}

\begin{abstract}
Introduction: Single-port access laparoscopic lateral segmentectomy (LLS) has been developed as a novel minimally invasive surgery. We have experience with this LLS technique.

Aim: To report our technique and patients' postoperative course in a series of single-port access LLS performed in our department. We also examine the cosmetic outcome, safety, and utility of the procedure.

Material and methods: Between February 2010 and October 2016, 54 patients who underwent single- or multiple-port laparoscopic or open lateral segmentectomy (LS) were retrospectively analyzed with respect to cosmetic outcome, safety, and utility.

Results: In the single LLS group, the laparoscopic procedure was successfully completed for all 14 patients. The median operative time was significantly shorter in the single LLS group (123 min; range: 50-270 min) than in the other groups. Estimated blood loss was also significantly lower in the single LLS group (10 ml; range: 0-330 ml). During the first 7 postoperative days, the visual analog scale pain score and the use of additional analgesia were not significantly different between groups. The single LLS group had a 7.1\% complication rate (Clavien-Dindo classification > IIIA); this was not significantly different between groups.

Conclusions: Single-port access LLS is a procedure with excellent cosmetic results, although, with regard to invasiveness, there are no major differences from conventional LLS.
\end{abstract}

Key words: single port access, laparoscopic lateral segmentectomy, cosmetics, visual analog scale, crossing hands technique.

\section{Introduction}

In the past two decades, laparoscopic surgery has advanced significantly as a substitute for conventional laparotomy in many fields, including gastroenterological surgery, due to its minimally invasive nature. Of the types of laparoscopic surgery, laparoscopic lateral segmentectomy (LLS) has been adopted worldwide since Azagra et al. [1] reported the use of the procedure for benign hepatic tumors.

Following the popularization of laparoscopic surgery, research and development of natural orifice transluminal endoscopic surgery (NOTES), a surgi- cal operation that does not create incisions in the body wall, was developed with the aim of further establishing minimally invasive operative procedures; NOTES has since been applied for cholecystectomy and appendectomy [2]. There are many issues remaining to be resolved with NOTES; however, it is expected to be a minimally invasive operative procedure in the future.

Operative procedures with a reduced number of port insertion incisions (reduced port surgery - RPS) in order to improve esthetic outcome and minimize abdominal wall destruction have attracted much

\section{Address for correspondence}

Yoshihiro Inoue MD, Department of General and Gastroenterological Surgery, Osaka Medical College Hospital, 2-7 Daigaku-machi,

Takatsuki City, Osaka 569-8686, Japan, phone: +81 072(683)1221, fax: +81 072(685)2057, e-mail: sur129@osaka-med.ac.jp 
attention. Single-incision laparoscopic surgery has been developed as a novel minimally invasive surgery, and has been used primarily for cholecystectomy and appendectomy [3]. Its safety has been demonstrated and it is being applied to various surgical techniques. Reduced port surgery has been used to perform LLS; at our institution, we have performed single-port access LLS in 14 patients beginning in 2010.

\section{Aim}

Here, we report our technique and patients' postoperative course in a series of single-port access LLS performed in our department. We also examine the cosmetic outcome, safety, and utility of the procedure.

\section{Material and methods}

\section{Patient population and selection}

The medical records of 54 patients who underwent laparoscopic or open lateral segmentectomy for liver disease from February 3, 2010 to October 26, 2016 at Osaka Medical College Hospital were reviewed. All patients were fully informed of the study design according to the Ethics Committee on Clinical Investigation of Osaka Medical College Hospital (No. 1828 and 1997) and provided written informed consent.

In September 9, 2009, pure LLS for hepatocellular carcinoma was introduced at our institution. Today, tumor size less than $5 \mathrm{~cm}$ is the main criterion for laparoscopic hepatic resection; tumor number and tumor location are not criteria. However, patients with portal or hepatic vein involvement and invasion to adjacent organs are not considered candidates for laparoscopic hepatic resection.

In October 13, 2010, single-port access LLS (single LLS) for resection of liver metastasis from colorectal cancer was initiated at our institution. Based on preoperative computed tomography (CT) imaging, LLS was performed using single-port access laparoscopy when the distance from the umbilical part of the left branch of the portal vein to the tumor margin was $10 \mathrm{~mm}$ or more, conventional laparoscopy when 2-10 $\mathrm{mm}$ or less, and laparotomy if less than $2 \mathrm{~mm}$.

From February 2010 to October 2016, single LLS for liver tumors was performed in 14 patients who provided informed consent. Conventional laparo- scopic lateral segmentectomy (conventional LLS), consisting of laparoscopic hepatic resection using multiple ports for a maximum liver tumor size $\leq 5 \mathrm{~cm}$, was performed in 16 patients. Open lateral segmentectomy (open LS) was performed in 11 patients from February 2010 to October 2016. These 41 patients underwent lateral segmentectomy with no other concomitant surgical (i.e., colorectal) procedures.

Preoperative workup consisted of a specified protocol, including blood examinations, abdominal ultrasound, angio-CT scan, magnetic resonance imaging, and fluorodeoxyglucose-positron emission tomography. Liver volumetry was estimated using the Synapse Vincent system (Fujifilm, Tokyo, Japan) and multidetector CT. Evaluation of hepatic function was accomplished the using indocyanine green retention rate at $15 \mathrm{~min}$ (ICG-R15, reference range: $<10.0 \%$ ) and the Child-Pugh classification [4] of liver dysfunction.

\section{Surgical procedure}

In this series, all procedures were performed by three experienced hepatobiliary surgeons ( $\mathrm{YI}, \mathrm{FH}$, $\mathrm{KU})$ during the study period. All patients received potentially curative hepatic resection with removal of gross tumor with negative macroscopic margins.

All operations were performed with the patient under general anesthesia. Briefly, the patients were placed in the "French" position, with the first operator standing between the patient's legs. The second operator (the scopist) stood on the left side of the patient. A $2.0 \mathrm{~cm}$ umbilical vertical incision was performed for the Alexis wound retractor ( $S$ size: Applied Medical; Rancho Santa Margarita, CA, USA) by the open laparoscopy technique. The glove-port system was produced using 5-, 5-, and 12-mm laparoscopic ports through the first, second, and fourth finger of the surgical glove, respectively (Photo 1) [3]. The gas tubing ligated on the thumb of the glove was connected directly. After the glove-port system was placed in its introducer and inserted into the abdomen, continuous carbon dioxide $\left(\mathrm{CO}_{2}\right)$ pneumoperitoneum was induced at a pressure limit of $12 \mathrm{~mm} \mathrm{Hg}$ and flow of $6 \mathrm{l} / \mathrm{min}$ to decrease the risk of gas embolism. A 5-mm flexible laparoscope (Olympus Inc., Tokyo, Japan) was used for visual inspection of the abdominal cavity. The liver was evaluated in all cases with the aid of intraoperative laparoscopic ultraso- 
nography (Prosound a7; Hitachi Aloka Medical, Ltd., Tokyo, Japan). The round ligament of the liver was preserved, and the falciform ligament was lifted.

A number of techniques were perfected preoperatively and performed so that the instruments were not interfering with one another. Crossing hands and reflecting the camera facilitates internal triangulation, mainly on the camera, of the operating instruments (Photo $2 \mathrm{~A}$ ). The proposed parenchymal transection line was along the round ligament of the liver. With the right hand of the first operator, the superficial parenchymal transection of the liver (no more than $1 \mathrm{~cm}$ deep in the parenchyma) was achieved using the surgical tissue management system (Thunderbeat; Olympus Inc., Tokyo, Japan) (Photo 2 B). With the left hand of the first operator, the lateral segment of the liver was retracted to the outside. Small vessels were coagulated using a soft-coagulation system or surgical tissue management system. This leaves intact arteries, veins, and bile ducts, which run to segments 2 and 3, crossing the line of division. An articulating laparoscopic stapler (Endo GIA Ultra Universal Stapler; Covidien, Tokyo, Japan) was transected at the vascular pedicles with the ideal angle of staple deployment. Finally, the hepatic vein was also sectioned using a laparoscopic stapler. The resected, undivided specimen was placed in a plastic retrieval bag and removed

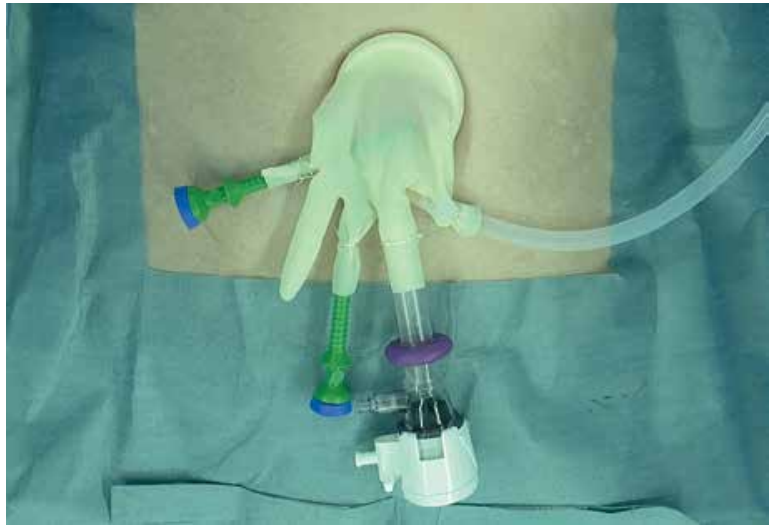

Photo 1. The glove-port system. Three laparoscopic ports were inserted through the first, second, and fourth fingers of the surgical glove. The gas tubing ligated on the thumb of the glove was connected directly

through the umbilical incision enlarged to $5 \mathrm{~cm}$. Abdominal drainage was usually omitted.

Details of the surgical technique in conventional four-port laparoscopic lateral segmentectomy routinely used in our department have been described in previous reports [5]. Four (and on rare occasion five) trocars (5-, 5-, 12-, and 12-mm) were used.

In the open lateral segmentectomy group, epidural analgesia was used. The open lateral segmentectomy was performed via an epigastric middle inci-
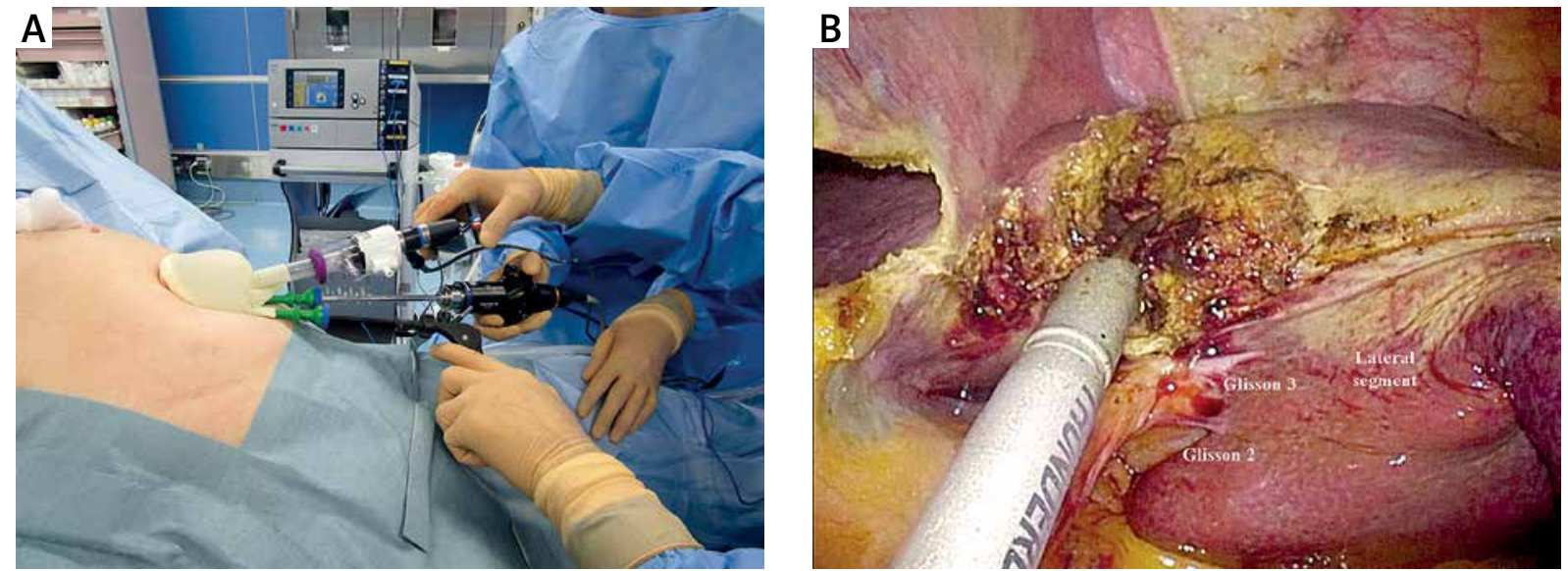

Photo 2. Crossing hands technique. A - Separation of the trocars allowed full movement of the instruments. The tips of both handed forceps of the first operator were crossed in the abdominal cavity. B - With the right hand of the first operator, parenchymal transection of the liver was achieved. With the left hand of the first operator, the lateral segment of the liver was retracted to the outside. By crossing the left and right surgical instruments and using the laparoscope in the center, it is possible to maintain the principle of triangulation. Furthermore, the liver transection line from the umbilicus to the root of the left hepatic vein is straight, and the cut surface also becomes sagittal 
sion. Intraoperative ultrasonography was performed routinely. The hepatic pedicle was always isolated to enable performance of the Pringle maneuver when needed. Parenchymal transection was achieved with the ultrasonic dissector and surgical tissue management system. Intraparenchymal control of the major vessels was obtained with clips or nonabsorbable sutures [5-7].

\section{Preoperative factors}

Data examined included preoperative, surgical, and pathological factors. Preoperative factors investigated were age, sex, viral infection status, history of previous operations, platelet count, albumin, total bilirubin, prothrombin time (PT), Child-Pugh classification, and ICG-R15.

\section{Surgical and pathological factors}

Surgical factors included surgical duration, intraoperative blood loss, and blood transfusion requirements. Pathological factors evaluated included the size of the largest tumor, number of tumors, number of hepatic resections, surgical margin status, and microscopic curative resection.

\section{Postoperative evaluation}

The following parameters were evaluated: white blood cell (WBC) counts, C-reactive protein (CRP), aspartate aminotransferase (AST) level, alanine aminotransferase (ALT) level, platelet count, albumin, total bilirubin, $\mathrm{PT}$, transfusion rate, pathological margins, postoperative complications, 30-day mortality, and hospital stay.

All patients who underwent laparoscopic and open lateral segmentectomy were monitored for the assessment of pain. A visual analog scale (VAS; 0-100) and analgesic use were used for pain assessment 1, 2, 4, and 7 days after surgery.

Morbidity was graded according to Clavien's classification [8, 9]. Surgical site infections were defined according to the CDC's National Nosocomial Infection Surveillance (NNIS) system [10]. Post-hepatectomy liver failure (PHLF) was diagnosed based on the International Study Group of Liver Surgery (ISGLS) definition [11].

\section{Patient follow-up}

Patients were closely followed until November 30, 2016. Surveillance imaging, including ultraso- nography and contrast-enhanced CT, and liver function were monitored at regular intervals.

\section{Statistical analysis}

Continuous variables are expressed as median \pm standard deviation (SD). Continuous variables were compared using Student's $t$-test and the $\chi^{2}$ test. Univariate analyses of categorical variables were compared using the likelihood-ratio test, Fisher's exact test or Mann-Whitney test, as appropriate. $P<0.05$ was considered significant. Multivariate analyses were performed by Cox proportional hazards regression; $p<0.05$ was considered significant. All statistical analyses were performed using JMP version 12 (SAS Institute, Inc., Cary, NC, USA).

\section{Results}

Table I reports demographic data of the three groups. There were no significant differences in the demographic or operative characteristics between groups. The number and size of the tumors were similar between groups.

Table II shows surgical outcomes. In the single LLS group, the laparoscopic procedure was successfully completed for all 14 patients. Median operative time was significantly shorter in the single LLS group (123 min; range: 50-270 $\mathrm{min}$ ) than in the other groups ( $p=0.0005$ and 0.0019 , respectively). Estimated blood loss was significantly lower in the single LLS group (10 $\mathrm{ml}$; range: $0-330 \mathrm{ml}$ ) than in the conventional LLS group (150 ml; range: 0-1450 ml) $(p=0.0402)$. During the first 7 postoperative days, the VAS score was not significantly different between groups (Table II). There was also no significant difference in the use of additional analgesia between groups.

Postoperatively, serum total bilirubin, albumin, PT, AST, ALT, WBC count, and CRP level, especially on the peak day, were not significantly different between groups.

The single LLS group had a 7.1\% complication rate (Clavien-Dindo classification > IIIA), which was not significantly different between groups ( $p=$ 0.4828 and 1.0000 , respectively). Overall in-hospital mortality included 1 (4.0\%) patient due to postoperative hepatectomy liver failure in the open LS group $(p=1.0000)$.

Postoperative medical treatment was similar for the three groups, including intravenous electrolyte 
Table I. Demographic data of patients who underwent lateral segmentectomy

\begin{tabular}{|c|c|c|c|c|}
\hline Parameter & Single LLS & Conventional LLS & Open LS & $\begin{array}{c}P \text {-value } \\
\text { Single vs. convent } \\
\text { Single vs. open } \\
\text { Convent vs. open }\end{array}$ \\
\hline Number & 14 & 15 & 25 & \\
\hline Age [years] & $72(57-82)$ & $70(62-78)$ & $66(28-82)$ & $\begin{array}{l}0.7215 \\
0.1492 \\
0.1926\end{array}$ \\
\hline Sex (male : female) & $8: 6$ & $9: 6$ & $18: 7$ & $\begin{array}{l}1.0000 \\
0.4816 \\
0.4983\end{array}$ \\
\hline \multicolumn{5}{|l|}{ Pathology: } \\
\hline $\mathrm{HCC} / \mathrm{ICC}$ & 8 & 5 & 12 & $\begin{array}{l}0.2723 \\
0.7411 \\
0.5115\end{array}$ \\
\hline Metastasis/others & 6 & 10 & 13 & \\
\hline Hepatitis viral infection & $6(42.9 \%)$ & $7(46.7 \%)$ & $10(40.0 \%)$ & $\begin{array}{l}1.0000 \\
1.0000 \\
0.7486\end{array}$ \\
\hline Diabetes mellitus & $5(35.7 \%)$ & $7(46.7 \%)$ & $10(40.0 \%)$ & $\begin{array}{l}0.7104 \\
1.0000 \\
0.7486\end{array}$ \\
\hline Body mass index $\left[\mathrm{kg} / \mathrm{m}^{2}\right]$ & $23.2(15.6-29.2)$ & $21.1(17.9-29.4)$ & $22.6(18.3-29.7)$ & $\begin{array}{l}0.6130 \\
0.9878 \\
0.5151\end{array}$ \\
\hline Albumin $[\mathrm{g} / \mathrm{dl}]$ & $4.1(2.9-4.6)$ & $4.1(3.0-4.7)$ & $4.2(3.2-4.8)$ & $\begin{array}{l}0.8081 \\
0.3816 \\
0.5426\end{array}$ \\
\hline Total bilirubin [mg/dl] & $0.5(0.3-1.2)$ & $0.5(0.4-2.1)$ & $0.5(0.3-2.2)$ & $\begin{array}{l}0.4047 \\
0.4452 \\
0.8824\end{array}$ \\
\hline Prothrombin time (\%) & $98(46-136)$ & $108(81-122)$ & $104(83-146)$ & $\begin{array}{l}0.1522 \\
0.4769 \\
0.5491\end{array}$ \\
\hline ICGR-15 (\%) & $14.8(8.7-22.9)$ & $12.2(4.9-28.0)$ & $10.4(1.0-19.4)$ & $\begin{array}{c}0.57432 \\
0.1307 \\
0.5999\end{array}$ \\
\hline Child's grading (A/B) & $14 / 0$ & $12 / 3$ & $25 / 0$ & $\begin{array}{l}0.2241 \\
1.0000 \\
0.0561\end{array}$ \\
\hline Number of tumors & $1(1-3)$ & $1(1-4)$ & $1(1-24)$ & $\begin{array}{l}0.1470 \\
0.0676 \\
0.1075\end{array}$ \\
\hline Size of largest tumor [cm] & $2.7(1.3-7.5)$ & $2.9(2.0-6.2)$ & $2.9(0.9-28.0)$ & $\begin{array}{l}0.3100 \\
0.3622 \\
0.5937\end{array}$ \\
\hline Repeat operation (yes/no) & $14 / 0$ & $15 / 0$ & $23 / 2$ & $\begin{array}{l}1.0000 \\
0.5277 \\
0.5192\end{array}$ \\
\hline
\end{tabular}

LLS - laparoscopic lateral segmentectomy, LS - lateral segmentectomy, convent - conventional, HCC - hepatocellular carcinoma, ICC - intrahepatic cholangiocellular carcinoma, ICGR-15 - indocyanine green retention rate at $15 \mathrm{~min}$. 
Table II. Surgical outcomes of patients who underwent lateral segmentectomy

\begin{tabular}{|c|c|c|c|c|}
\hline Parameter & Single LLS & Conventional LLS & Open LS & $\begin{array}{c}P \text {-value } \\
\text { Single vs. convent } \\
\text { Single vs. open } \\
\text { Convent vs. open }\end{array}$ \\
\hline Number & 14 & 15 & 25 & \\
\hline Convert & 0 & 2 & - & $\begin{array}{c}0.2323 \\
- \\
-\end{array}$ \\
\hline Operative time [min] & $123(50-270)$ & $233(108-460)$ & $225(117-460)$ & $\begin{array}{c}0.0005^{\star} \\
0.0019^{\star} \\
0.4871\end{array}$ \\
\hline Blood loss [ml] & $10(0-330)$ & $150(0-1450)$ & $195(0-910)$ & $\begin{array}{c}0.0402^{\star} \\
0.0350^{\star} \\
0.8567\end{array}$ \\
\hline Blood transfusion & 0 & $2(13.3 \%)$ & 0 & $\begin{array}{c}0.4828 \\
- \\
0.1346 \\
\end{array}$ \\
\hline Surgical margin [mm] & $11(2-30)$ & $10(1-60)$ & $5(0-24)$ & $\begin{array}{l}0.0883 \\
0.1801 \\
0.7084\end{array}$ \\
\hline Curative resection, RO & $14(100 \%)$ & $15(100 \%)$ & $21(84.0 \%)$ & $\begin{array}{l}1.0000 \\
0.1140 \\
0.0978 \\
\end{array}$ \\
\hline \multicolumn{5}{|l|}{ VAS: } \\
\hline Day 1 after operation & $33(25-60)$ & $50(20-72)$ & $50(30-80)$ & $\begin{array}{l}0.4509 \\
0.1784 \\
0.4012\end{array}$ \\
\hline Day 2 & $21(0-50)$ & $25(0-79)$ & $30(0-59)$ & $\begin{array}{l}0.5219 \\
0.7055 \\
0.7622\end{array}$ \\
\hline Day 4 & $10(0-10)$ & $15(0-52)$ & $5(0-50)$ & $\begin{array}{l}0.4479 \\
0.5987 \\
0.7950\end{array}$ \\
\hline Day 7 & $3(0-6)$ & $0(0-5)$ & $5(0-50)$ & $\begin{array}{l}0.6920 \\
0.4432 \\
0.5436\end{array}$ \\
\hline \multicolumn{5}{|c|}{ Use of additional analgesia: } \\
\hline Day 1 after operation & $1(0-2)$ & $1(1-2)$ & $2(0-3)$ & $\begin{array}{l}0.0728 \\
0.1020 \\
0.5393\end{array}$ \\
\hline Day 2 & $0(0-2)$ & $1(0-3)$ & $1(0-1)$ & $\begin{array}{l}0.6419 \\
0.8250 \\
0.4509\end{array}$ \\
\hline Day 4 & $0(0-2)$ & $0(0-2)$ & $0(0-1)$ & $\begin{array}{l}0.8417 \\
0.1898 \\
0.2186\end{array}$ \\
\hline Day 7 & $0(0-1)$ & $0(0-0)$ & $0(0-0)$ & $\begin{array}{c}0.0877 \\
0.0552 \\
-\end{array}$ \\
\hline
\end{tabular}


Table II. Cont.

\begin{tabular}{|c|c|c|c|c|}
\hline Parameter & Single LLS & Conventional LLS & Open LS & $\begin{array}{l}P \text {-value } \\
\text { Single vs. convent } \\
\text { Single vs. open } \\
\text { Convent vs. open }\end{array}$ \\
\hline \multicolumn{5}{|l|}{ Complications: } \\
\hline $\begin{array}{l}\text { Clavien-Dindo classifi- } \\
\text { cation > IIIA }\end{array}$ & $1(7.1 \%)$ & $0(0 \%)$ & $2(8.0 \%)$ & $\begin{array}{l}0.4828 \\
1.0000 \\
0.5192\end{array}$ \\
\hline Hospital mortality & 0 & 0 & $1(4.0 \%)$ & $\begin{array}{c}- \\
1.0000 \\
-\end{array}$ \\
\hline $\begin{array}{l}\text { Postoperative hospital } \\
\text { stay [days] }\end{array}$ & $9(5-22)$ & $9(7-38)$ & $10(6-42)$ & $\begin{array}{l}0.2340 \\
0.3665 \\
0.6624\end{array}$ \\
\hline
\end{tabular}

LLS - laparoscopic lateral segmentectomy, LS - lateral segmentectomy, convent - conventional, VAS - visual analog scale.

and balanced fluid solutions. Oral intake of fluid started on postoperative day 2 . The median postoperative length of intravenous medicine was 5 days in all groups. The overall median postoperative length of hospital stay was 9 days (range: 5-22 days) in the single LLS group; there was no significant difference between groups ( $p=0.2340$ and 0.3665 , respectively).

\section{Discussion}

In the era of laparoscopic surgery, reduced postoperative pain, fewer adhesions, early recovery, and cosmetically acceptable results are major goals to achieve better patient care. Several studies [12-14] have demonstrated that less postoperative pain and early recovery were associated with reduction in either the size or number of ports.

The performance of the single-incision laparoscopic operative procedure is rapidly spreading in many fields. However, since Gaujoux et al. reported the use of single-incision laparoscopic hepatectomy in a series of 5 patients in 2010 [15], there have been few studies concerning single-port access LLS [16]. Therefore, we report here the features of single-port access LLS at our institution.

First, the greatest advantage is cosmetic outcome. We have performed conventional LLS using an umbilical incision plus three ports, for a total of four ports, but single LLS uses only an umbilical incision. Because the size of the umbilical incision is defined by the size of the lateral segment $(3-5 \mathrm{~cm})$, and there are no differences from conventional LLS, cosmetic outcomes are naturally superior in com- parison with other procedures. Cosmetic results are very important, especially for young female patients.

The next issue is invasiveness of the procedure. In the present study, we found differences in operation time and intraoperative blood loss between groups. In the case of single LLS, patients had a distance of $1 \mathrm{~cm}$ or more between the tumor and the umbilical part of the left branch of the portal vein; thus, bias was present when selecting patients. The reasons for this are that, in comparison with conventional LLS, the major vessels and hepatic parenchyma to segments 2 and 3 are handled using the staplers; furthermore, in comparison with open LS, abdominal closure can be performed in a shorter time. However, we found no significant differences in the main factors related to invasiveness, specifically postoperative laboratory data and postoperative hospital length of stay. Postoperative pain assessment did not demonstrate superiority of the single incision technique. This may be due to the fact that in conventional LLS, the extended umbilical incision is the main cause of postoperative pain, rather than port insertion incisions other than the umbilicus.

What are the disadvantages of single-port access LLS? In single LLS, because multiple surgical instruments are inserted via one incision to approach the lesion, mutual interference of surgical instruments tends to occur. In addition, in some cases, due to interference of the forceps, sufficient traction cannot be obtained and it may be difficult to create an optimal visual field for the surgical site. However, it is 
our opinion that these issues can be solved by using the laparoscope in the center and crossing the left and right surgical instruments. Thus, the triangular formation made by the left and right forceps and the laparoscope can be secured. Furthermore, due to the triangular formation, the liver transection line from the umbilicus is straight, and the cut surface also becomes sagittal; as a result, operative treatment can be performed with a relatively favorable field of view.

The most important point to consider is hemorrhage control. Hemostatic control is difficult in some cases of LLS, including both the single- and multiple incision methods. However, by crossing the left and right surgical instruments to ensure a triangular formation, it is possible to perform the operation while directly viewing the liver stumps of the remnant side and the excised side. By doing so, the operation could be completed in our facility in all cases using a single port and without excessive blood loss. Regarding hemorrhage control, the single-port access method is not inferior to the conventional method.

In comparison with conventional LLS, the number of forceps used in single-port access LLS can be reduced. For this reason, there are disadvantages concerning operability of the forceps. In order to compensate for these drawbacks, the development of various devices has been actively conducted [17]. The glove-port system is one of these innovations. In this system, a single $2.0 \mathrm{~cm}$ umbilical incision is large enough to pass three devices through, and additional forceps can be added through the three fingers of the surgical glove without additional incisions. In this way, further improvements in laparoscopic surgery due to surgical instrument and device innovations can be expected in the future.

\section{Conclusions}

Single-port access LLS is a procedure with excellent cosmetic results. With regard to invasiveness, there are no major differences from conventional LLS, but the use of a single incision allows the procedure to be completed with shorter operative duration and reduced intraoperative blood loss. However, because the number of patients in the present study is small and there were various biases present, the level of evidence presented here is low. Future studies, including randomized controlled trials and meta-analyses, are necessary.

\section{Acknowledgments}

We are very grateful to all of the patients who volunteered to join this study.

\section{Conflict of interest}

YI was supported by Mitsui Life Social Welfare Foundation.

The authors declare no conflict of interest.

\section{References}

1. Azagra JS, Goergen M, Gilbart E, et al. Laparoscopic anatomical (hepatic) left lateral segmentectomy-technical aspects. Surg Endosc 1996; 10: 758-61.

2. Atallah S, Martin-Perez B, Keller D, et al. Natural-orifice transluminal endoscopic surgery. Br J Surg 2015; 102: e73-92.

3. Asakuma M, Hayashi M, Komeda K, et al. Impact of single-port cholecystectomy on postoperative pain. Br J Surg 2011; 25 : 649-50.

4. Pugh RN, Murray-Lyon IM, Dawson JL, et al. Transection of the oesophagus for bleeding oesophageal varices. Br J Surg 1973; 60: 646-9.

5. Inoue $\mathrm{Y}$, Hayashi M, Tanaka R, et al. Short-term results of laparoscopic versus open liver resection for liver metastasis from colorectal cancer: a comparative study. Am Surg 2013; 79 : 495-501.

6. Inoue Y, Hayashi M, Komeda K, et al. Resection margin with anatomic or nonanatomic hepatectomy for liver metastasis from colorectal cancer. J Gastrointest Surg 2012; 16: 1171-80.

7. Inoue Y, Tanaka R, Komeda K, et al. Fluorescence detection of malignant liver tumors using 5-aminolevulinic acid-mediated photodynamic diagnosis: principles, technique, and clinical experience. World J Surg 2014; 38: 1786-94.

8. Dindo D, Demartines N, Clavien PA. Classification of surgical complications: a new proposal with evaluation in a cohort of 6336 patients and results of a survey. Ann Surg 2004; 240: 205-13.

9. Clavien PA, Barkun J, de Oliveira ML, et al. The Clavien-Dindo classification of surgical complications: five-year experience. Ann Surg 2009; 250: 187-96.

10. Mangram AJ, Horan TC, Pearson ML, et al. Guideline for prevention of surgical site infection, 1999 Centers for Disease Control and Prevention (CDC) Hospital Infection Control Practices Advisory Committee. Am J Infect Control 1999; 27: 97-132.

11. Rahbari NN, Garden OJ, Padbury R, et al. Posthepatectomy liver failure: a definition and grading by the International Study Group of Liver Surgery (ISGLS). Surgery 2011; 149: 713-24.

12. Poon CM, Chan KW, Lee DW, et al. Two-port vs four-port laparoscopic cholecystectomy. Surg Endosc 2003; 17: 1624-7.

13. Ramachandran CS, Arora V. Two-port laparoscopic cholecystectomy: an innovative new method for gallbladder removal. J Laparoendosc Adv Surg Tech A 1998; 8: 303-8.

14. Lomanto D, De Angelis L, Geci V, et al. Two-trocar laparoscopic cholecystectomy: a reproducible technique. Surg Laparosc Endosc Percutan Tech 2001; 11: 248-51. 
15. Gaujoux S, Kingham TP, Jarnagin WR, et al. Single-incision laparoscopic liver resection. Surg Endosc 2011; 25: 1489-94.

16. Patel AG, Belqaumkar AP, James J, et al. Single-incision laparoscopic left lateral segmentectomy of colorectal liver metastasis. Surg Endosc 2011; 25: 649-50.

17. Ban D, Kudo A, Irie T, et al. Advances in reduced port laparoscopic liver resection. Asian J Endosc Surg 2015; 8: 11-5.

Received: 22.08.2017, accepted: 14.09.2017. 